\title{
NBSIR 75.677 \\ Hazard Assessment of Aluminum Electrical Wiring in Residential Use
}

Elaine D. Bunten, John L. Donaldson, Eugene C. McDowell

Product Systems Analysis Division Institute for Applied Technology

National Bureau of Standards

Washington, D. C. 20234

\section{December 1974}

Final Report

Prepared for

U. S. Consumer Product Safety Commission

Washington, D. C. 20207 

NBSIR 75-677

\section{HAZARD ASSESSMENT OF ALUMINUM ELECTRICAL WIRING IN RESIDENTIAL USE}

Elaine D. Bunten, John L. Donaldson, Eugene C. McDowell

Product Systems Analysis Division

Institute for Applied Technology

National Bureau of Standards

Washington, D. C. 20234

December 1974

Final Report

Prepared for

U. S. Consumer Product Safety Commission

Washington, D.C. 20207

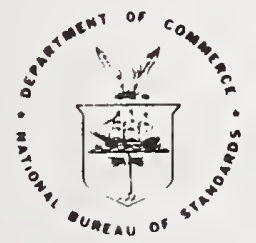

U. S. DEPARTMENT OF COMMERCE

NATIONAL BUREAU OF STANDARDS, Richard W. Roberts. Director 

TABLE of CONTENTS

\section{Page}

Acknowledgements

iv

Abstract

1. Introduction and Executive Summary 1

1.1 Problem Statement 1

1.2 Purpose of this Document 1

1.3 Report Highlights 2

2. Background 3

3. Data Requirements and Data Characteristics 6

3.1 Data Requirements

3.1.1 Data Required to Determine Nature and Extent of Use of Aluminum Wiring 8

3.1.2 Data Required to Determine Leve1 of Risk to Consumers 9

3.1.3 Data Required to Describe the Performance of Aluminum Wiring in Residences

3.2 Characteristics Required of the Data and Data Collection Procedures

3.2.1 Definition of Objectives 13

3.2.2 Sampling Procedures, If Any 14

3.2.3 Potential Sources of Observation Bias 14

3.2.3.1 Nonobservation 14

3.2.3.2 Observing and Recording Data 15

3.3 Summary 16 
Contents (continued)

Page

4. Field Data and Data Sources Examined 17

$\begin{array}{lll}4.1 & \text { Approach } & 17\end{array}$

4.2 Summary of Data Sources Examined and

$\begin{array}{lll}\text { 4.2.1 Systematic Documentation } & 19\end{array}$

4.2.2 Fire Investigations 20

4.2.3 Incomplete Reporting of Electrical Failures 21

4.2.4 Biases 21

4.3 Summary and Evaluation of Information Found 21

$\begin{array}{lll}4.3 .1 & \text { General } & 21\end{array}$

4.3.2 Specific Sources of Information 24

4.3.2.1 Consumer Product Safety Commission 24

4.3.2.2 Underwriters' Laboratories, Inc. Field Surveys 25

4.3.2.3 American Plan Corporation 29

4.3.2.4 International Association of Electrical Inspectors

4.3.2.5 National Fire Protection Association 30

4.3.2.6 Prince George's County, Maryland 30

4.3.2.7 Washington, D. C. 31

4.3.2.8 Huntington Beach, California 31

4.3.2.9 Summary 31

4.4 State and Local Restrictions on the Use of
Aluminum Wiring

4.5 Estimated Numbers of Homes with Aluminum Wiring 36

$\begin{array}{lll}4.6 & \text { Conclusion } & 38\end{array}$ 
Contents (continued)

Page

5. Satisfying the Data Requirements 39

5.1 The Macro Study 41

5.1.1 Sample for the Macro Study 42

5.1.2 Data Collection for the Macro Study 42

5.2 The Micro Study 43

5.2.1 Sample for the Micro Study 45

5.2.2 Data Collection for the Micro Study 45

$\begin{array}{lll}5.3 & \text { Summary } & 48\end{array}$

$\begin{array}{lr}\text { References } & 49\end{array}$ 


\section{ACKNOWLEDGEMENTS}

The authors wish to thank C. W. Hurley and W. S. Williams of the Technical Analysis Division, NBS, for their direct assistance in this study. Also, the following NBS staff members' consultations are gratefully acknowledged: L. D. Ballard, R. L. Cilimberg, M. G. Domsitz, L. S. Joe1, S. J. Kim, L. W. Masters, L. Oberlander, J. A. Rockett, J. R. Sorre11s and R. O. Stone.

Many persons outside NBS provided valuable help. Deserving special mention are: W. H. King, Consumer Product Safety Commission; R. H. Hanson, D. I. Siskind and A. F. Young, Bureau of the Census; T. J. D'Agostino, Underwriters' Laboratories, Inc.; C. L. Duncan, Huntington Beach (CA) Fire Department; and R. J. Ke1ly, Washington (D.C.) Fire Department.

The authors thank the following members of NBS for their typing services: M. Abbott, P. Droneberg and L. Freeman. 
HAZARD ASSESSMENT OF ALUMINUM ELECTRICAL WIRING IN RESIDENTIAL USE

Elaine D. Bunten

John L. Donaldson

Eugene C. McDowe11

\begin{abstract}
In the mid-1960s, aluminum wire began to be used in significant quantities for residential branch-circuit wiring. Reports of problems from various localities in the U.S. raised serious concern and controversy as to the safety of this application. An official determination on this matter is within the jurisdiction of the Consumer Product Safety Commission. This report reviews the history of the use of aluminum in residential wiring and describes the characteristics essential to data to be used to evaluate the performance of aluminum wiring in the field. The examination of existing field data shows that no available data have the characteristics necessary to develop a reliable estimate of the level of risk to consumers associated with aluminum wiring. Neither can the available data be used to establish the relative risk of aluminum compared to copper wiring. There is only a gross estimate of the extent to which aluminum wiring is now in use in U. S. residences. Statistically sound estimates of risk would be possible only after data collection on a large scale.
\end{abstract}

Key words: Aluminum wire; consumer product safety; electical failures; electrical fires; electrical wiring; fire hazards 

Hazard Assessment of Aluminum Electrical Wiring in Residential Use

\section{Introduction and Executive Summary}

\subsection{Problem Statement}

Under contract with the U.S. Consumer Product Safety Commission (CPSC), the Technical Analysis Division (TAD) of the National Bureau of Standards initiated a four-phased program of work concerning aluminum wiring in U.S. residences. The objectives of this work can be summarized as

Phase I: Identify, evaluate, and analyze existing field data to determine accessibility, validity, and reliability as a prerequisite to their being used to evaluate the use of aluminum electrical wiring in U.S. residences.

Phase II: If existing data are found to be inadequate to perform the evaluation cited above: identify additional data required, then design and carry out data collection with the concurrence of NBS and CPSC.

Phase III: Using existing and/or additionally collected data, estimate the extent of use of that wiring in U.S. residences and the level of risk* to the consumer associated with its use.

Phase IV: If the CPSC determines that aluminum electrical wiring presents an "unreasonable risk" to the public, examine and evalute alternative approaches for reducing the level of risk.

Phase I and parts of Phase II have been completed. The project was terminated by the CPSC before the remaining phases could be performed.

\subsection{Purpose of this Document}

This document is a final report summarizing the work that was completed. The report deals primarily with the data and data sources which were considered to have possible merit with regard to an assessment of the use of aluminum wiring in the field (i.e., reports of its performance as actually installed in U.S. housing). It presents and discusses inherent characteristics of aluminum wiring only in order to clarify the evaluation of existing sources of field data, or to explain additional data requirements. Included in the report are 
- A brief history of the use of aluminum electrical wiring in the United States;

- A brief resume of events and actions affecting the use of aluminum electrical wiring;

- A description of the characteristics essential to data to be used to evaluate the performance of aluminum wiring in the field;

- A general discussion of the adequacy of the existing data relative to the data requirements;

- An evaluation of certain specific sources of available field data;

- Identification of additional data requirements; and

- Recommendations and a general plan for additional data collection.

\subsection{Report Highlights}

The items included in this report result in the following observations:

- An examination of the history of events associated with the use of aluminum electrical wiring in U.S. residences supports the view that the use of aluminum conductors in residential applications has resulted in problems.

- The data which would be required to determine the nature and extent of any hazard associated with the use of aluminum conductors are identified and the requirements are used to evaluate existing field data.

- The examination of existing field data shows that no available data have the characteristics necessary to develop a statistical estimate of the level of risk to consumers associated with aluminum wiring. Neither can the available data be used to establish the relative risk of aluminum compared to copper wiring.

- Existing data cannot be used to establish that aluminum wiring presents no substantial hazard to consumers.

- Existing data can be used to provide only a very gross estimate of the extent to which aluminum wiring is now in use in U.S. residences.

- It would be possible to continue with Phase III of the current project only after a significant data collection effort has been undertaken. 


\section{Background}

Currently, aluminum and copper are the only commercial metals which are both available in sufficient quantities and have the necessary characteristics for general use as electrical conductors. (Sodium, niobium, silver, etc. are sometimes used as electrical conductors for special applications.) Copper was the first, and for many years the only metal used as an electrical conductor. (1)* Aluminum conductors were first formally recognized in the 1901 edition of the National Electrical Code (NEC). It was not until 1946, however, that Underwriters' Laboratories, Inc. (UL) labeled aluminum conductors. (Users of electrical equipment often use UL tests and certifications in their buying decisions.) Subsequent to the 1946 UL listing, (equipment is "listed" as it is approved) production and use of aluminum electrical cables in the larger (AWG \# 8 and larger) sizes became increasingly common. (2)

In the early 1950s UL undertook an examination of aluminum building wires and connectors because of "... anticipated development in the aluminum wire industry...". The samples for this investigation "...represented the first efforts of wire manufacturers to utilize aluminum for building wire". (3)

In February 1957, UL recognized nonmetallic-sheathed aluminum wire (the kind commonly used in much house wiring) and invited manufacturers to apply for labeling approval. Despite this, there appears to have been little production or use of aluminum electrical wire for use in residences prior to the 1960s, with 1966 generally being regarded as the year in which there was a significant increase in the production of aluminum electrical wire for use in homes. (2) Based on estimates by The Aluminum Association, approximately 23 million meters of aluminum cable in housewiring sizes were produced in the period 1960 through 1965; in 1966, approximately 36 million meters of such cable were produced; and from 1966 through 1971 approximately 737 million meters of such wire were produced. (4) (See Section 4.5 for a discussion of these estimates.)

The substitution of aluminum for copper in electrical (and other) applications has largely been due to economic rather than technical considerations. For example, in the early days of its commercial production, the cost per pound of aluminum was much higher than that of copper and there was no reason to use aluminum in electrical conductors.(5) The 1940 edition of a well known electrical engineering text, however, discusses the use of aluminum in high tension transmission lines and low tension bus-bars, and states, "Because aluminum wires have a greater diameter for the same conductance than copper wires, the use of aluminum in insulated wires is prohibited, at the usual prices of both metals, by the extra cost of insulation."(6) The National Materials Advisory Board states that "Aluminum started being used as an electrical conductor

ॠ

Numbers in parentheses indicate citations listed in the reference section at the end of this paper. 
when its price on a weight basis fell to about twice that of copper". (7) A comparison of the prices of the two metals between 1939 and 1970 shows that except for short periods of time, the price of copper relative to the price of aluminum has been steadily increasing. As of March 1971, a given volume of copper was five times more expensive than an equal volume of aluminum. (8) Since it requires a greater volume of aluminum than copper for the same electrical current carrying capacity and since the larger diameter of the aluminum wire would cause the cost of insulating aluminum to be higher, the cost of insulated aluminum wiring for a house at that time would have been about $37 \%$ of the cost of insulated copper wire for the same house. (5) As of early 1974 the cost of insulated aluminum wire for house wiring was about 50-60\% of the cost of insulated copper wire of equal current carrying capacity.

In 1966, UL began 1isting general use snap switches and attachmentplug receptacles specifically approved for use with aluminum or copper wire. (9) Prior to this date, based on their earlier investigation, (10) UL had considered all general use wiring devices (except for those using screwless push-in terminals) as acceptable for use with either aluminum or copper conductors. In 1966, UL stated that wiring devices could be used with aluminum conductors only when "(1) the terminal is of the wire binding screw type where the conductor is to be looped around the screw, or (2) on other types of terminals only when marked 'AL-CU'." (9)

At the same time (mid 1960s) that the relative prices of copper and aluminum led to an increase in the production of aluminum conductors, this same factor contributed toward changing the metals used in the screws and base plates of the termination devices from brass to plated steel (usually zinc plated). Laboratory tests made by Battelle Memorial Institute at a later date indicated that the use of zinc-plated steel with aluminum wire was not to be recommended since there are basic metallurgical incompatibilities between the plated screws and the aluminum wire in this application. (11)

By 1968, UL had begun to receive reports of difficulties in the field associated with aluminum electrical wiring. In 1969, UL and the National Electrical Manufacturers Association (NEMA) jointly undertook a survey to assess the status of aluminum wire usage in the field. Responses to a questionnaire were solicited from various electrical contractors, electrical inspectors, manufacturers, and users of electrical control equipment and related devices. (See Section 4.3 of this report for a discussion of this survey.) In May of 1971, UL initiated a test program directed toward the assessment of terminations of aluminum conductors at household duplex receptacles. (12) In December of 1972, in order to gather field data about problems with terminations of aluminum wire in residential branch circuit wiring, UL administered a second questionnaire, this time only to selected chief electrical inspectors throughout the U.S. In January 1974, UL administered a follow-up survey to some of the respondents to the 1972 survey. (See Section 4.3 of this report for a discussion of these surveys.) 
Throughout this period, a number of actions were taken which influenced the use of aluminum wiring and connectors to be used with aluminum wiring. A number of these are listed below:

- September 1970, UL revised its test specifications for the labeling of aluminum wire and emphasized the need for care in making connections with aluminum wire.

- January 1971, at least ten jurisdictions in Orange County, California had imposed a ban on all direct connections of aluminum wire to devices of 15 and 20 ampere rating. (13) (For other restrictions, see Section 4.4 of this report.)

- $\quad$ May 1971, UL required that aluminum wire manufacturers include precautionary installation instructions on packages of aluminum wire in sizes 8,10 , and 12 .

- June 1971, UL again began revising its test specifications for the labeling of aluminum wire.

- Effective September 1, 1971, UL required that all new devices eliminate the "AL-CU" marking unless they had been approved under a new test program. (14) (This action was announced in a July, 1971, UL Bulletin.)

- March 10, 1972, Leviton, a major manufacturer of devices sent a bulletin to all of its distributors saying that all Leviton devices available at that time would be marked with a notice that they should be used only with copper or copper-clad wire. (15)

- March 21, 1972, the General Engineering Committee of NEMA concluded that wiring devices then being sold were suitable for use only with copper wire or wire having copper or tinplated surfaces, and that those devices should not be used with other materials until their suitability had been established by extensive testing. (16)

- June 1972, an Ad Hoc Committee on Aluminum Terminations was formed with membership from industry and UL. Its purpose was to study and recommend procedures for improving the connectability of larger sizes (AWG \#12 and larger) of aluminum conductors. $(14,17)$

- June 1972, UL listed the first "CO/ALR" wiring device. The CO/ALR designation was given to wiring devices approved for use with aluminum conductors under a new test program. (17) 
- August 1972, an Ad Hoc Committee on the Use of Aluminum Conductors with Wiring Devices in Electrical Wiring Systems was organized by UL in order to allow for the exchange of information about actions that had been or should be taken to ensure proper and safe use of aluminum conductors and wiring devices. Members of the committee came from all areas of technical interest in aluminum conductors and wiring devices.

- September 1972, UL issued its revised test specifications for the listing of aluminum wire and approved the first wire to meet these specifications. (14)

- March 1973, final recommendation of the Ad Hoc Committee on the Use of Aluminum Conductors was released by UL to the technical press and to various groups associated with the installation of receptacles and snap switches in residential occupancies.

- Apri1 1973, UL proposed that wiring devices not listed for use with aluminum wire be provided with a precautionary notice.

- Effective January 15, 1974, UL required wiring devices not marked CO/ALR be marked either "Notice-Use only copper or copper-clad wire with this device", or "NoticeConnect only copper or copper-clad wire to this device", or "Notice-Use only devices marked CO/ALR with aluminum wire."

In brief, therefore, these events support the view that the use of aluminum conductors in U.S. residences has resulted in problems. The primary purpose of this report is to present the results of an examination of available field data. It was hoped that data might exist which could be used to estimate the nature, extent, and magnitude of these problems.

\section{Data Requirements and Data Characteristics}

Section 2 of this report outlines events which have sometimes explicitly and sometimes implicitly led to inferences that aluminum electrical wiring could present an unreasonable risk to consumers (i.e., occupants of houses, apartments, mobile homes, etc., which have been wired with aluminum). The primary purpose of this report, however, is to present the results of an examination of currently available field data about the use and performance of aluminum wiring in the field. In order to place this critical evaluation of existing data in perspective, it is necessary to state the criteria which were used in the evaluation. 
Section 3 outlines the data required, and describes the characteristics and attributes required of data to be used to determine (a) the nature and extent of use of aluminum wiring in U.S. residences, and (b) the risk to consumers associated with its use.

\subsection{Data Requirements}

In order to state the general data requirements, it is necessary first to cite some relevant facts about the use of aluminum wiring and wiring practices in residences:

- As stated in Section 2, aluminum wiring was rarely installed in residences in this country prior to 1960 , and not until 1966 was there substantial use of aluminum in this application.

- Many different alloys of aluminum have been produced in house wiring sizes. The performance of these different alloys varies according to differences in their mechanical and metallurgical properties.

- The type of wiring device used with aluminum conductors may significantly influence the performance of an aluminum-wired electrical system.

- There are four specific common uses of aluminum (and other) conductors within a residential unit: general purpose branch circuit conductors, service entrance cable, permanently connected appliance circuit conductors, and service busbar conductors. The performance demanded and that received from a conductor in each of these specific applications varies.

- Any one residential unit might contain no aluminum electrical wiring, might have aluminum in all electrical wiring, or might have any one or any combination of the specific aluminum wiring applications mentioned above.

- Electrical jurisdictions vary in the requirements imposed on electrical workers who install house wiring.

The NEC is a voluntary model code, but it has been widely adopted, in whole or in part, by local jurisdictions. The NEC allows insulated aluminum conductors in residences where copper is allowed on the basis that for the same size conductor, the current carrying capacity of aluminum is $84 \%$ of that of copper. (18) Some localities have enacted additional requirements for the installation of aluminum wiring, some follow the NEC, and some few probably have no codes at al1. 
The preceding facts are listed in order to make the point that "use of aluminum electrical wiring in residences" is a rather ambiguous concept. Data showing the presence or absence of (any) aluminum wiring in residences would not provide sufficient information to determine the nature and extent of use of aluminum wiring in the U.S. Similarly, analytical treatment of reports of failures attributed to aluminum wiring becomes useful only when data concerning the presence or absence of failures are qualified by other relevant data. Sections 3.1.1 and 3.1.2 describe the data required to determine the nature and extent of use of aluminum wiring in U.S. residences and the risk to consumers associated with its use.

\subsubsection{Data Required to Determine Nature and Extent of Use of Aluminum Wiring}

The requirements for data needed to make this determination include:

- A representative set of all types of U.S. housing (single and duplex houses, apartments, mobile homes);

- A representative (See Section 3.2) set of geographical areas;

- Categorization according to specific electrical application (branch circuit conductors, service entrance cable, appliance circuit conductors, service busbar conductors, and any combination of these;

- Categorization according to relevant installation date (e.g., pre and post UL 1isting of CO/ALR devices). It would be highly desirable for the data to be categorized by type of connector (AL-CU, copper pigtail, CO/ALR, "push" device, etc.)

The level of detail just described is based on the following hypothesis: If aluminum electrical wiring were established to present an unreasonable risk to consumers, that determination would necessarily be qualified with respect to some combination of the categories just listed. It is likely that varying levels of risk will be associ-ated with certain sets of conditions including specific use of the conductor, type of wiring device, installation practice, and installation date.

There are several conceptual matters that merit thorough consideration because they relate to the utilization of empirical data in support of policy decisions. The development of these matters into a framework for data collection and analysis will be one of the initial tasks of any further data acquisition effort. Although they will ultimately require more lengthy exposition, some of these conceptual matters are outlined here. It is important to distinguish the level of risk to the individual consumer from the total number of consumers at risk, and it is more important to recognize that a threshold between reasonable and unreasonable risk can be defined (by policy decision) in the context of individual 
risk as well as the context of national hazard. In the former case, data on the extent of use of aluminum wiring would not be required. In a practical sense, however, a judgment of unreasonable risk may be inseparable from the extent of risk in two respects. First, any rulemaking activity of the CPSC implies a judgment that the motivating conditions are a matter of national (as well as individual) interest. Second, the "unreasonableness" of a risk may be inextricably related to the ease or difficulty of reducing or eliminating the hazard; in the present context this implies such considerations as the relative availability (as well as cost) of aluminum and copper, and the impact on the affected meta1, wire, device and construction industries. Clearly, the ease of reducing a hazard may be different for existing installations and for future installations. Finally, there is no legal requirement that policy decisions meet a specified level of statistical defensibility. To the extent that the CPSC sees a need to undertake actions based on best judgment, the data requirements are relaxed.

\subsubsection{Data Required to Determine Leve1 of Risk to Consumers}

In addition to data regarding the nature and extent of the use of aluminum wiring (just discussed) there are other data required in order to determine a level of risk to consumers. But it is important to recognize that it is, or may be, possible to determine a level of risk associated with the use of aluminum wiring in residences, and even to identify ways of reducing that risk, without determining the exact mechanism of failure. As an extreme example, banning the use of aluminum wiring would eliminate any future problem, and rewiring existing residences would eliminate any existing problem. Neither of these solutions would require an understanding of the causes of the hazard.

Determination of the risk to consumers is a two part problem: determining the numbers of aluminum wiring failures that occur relative to the numbers of possible failures; and (b) determining what proportion of those failures result in bodily injury or death (or the threat thereof) to the occupants. To this two part problem must be added the CPSC counterpart problem: (c) determining whether the level of risk is reasonable.

Data required to approach the first two determinations are

- Data to establish the population of possible failures of aluminum wiring in a specified area. These data must be categorized by the other relevant factors including specific conductor application within residence, data of installation, etc.

- Data to establish numbers of failures in the same specified area (by specific application, by installation date). These data must also be categorized by type of failure: termination failure, wire failure, incipient failure, etc. 
- Data to establish the consequences of each failure in terms of occupant safety (by specific application, by installation date, etc.): fire or necessary conditions for fire, shock or necessary conditions for shock, etc. The data are specified in this way because actual injuries or deaths related to aluminum wire failures may be relatively rare events.

The data required for the determination of whether the risk is reasonable or not depends on decision criteria to be established by the CPSC. Possible data needs include data to compare the level of risk of aluminum wiring with other products, data concerning ways CPSC can affect codes or installation practices, and/or data to compare the cost of one decision outcome with others. Possible needs include

- Comparable data for copper wiring as specified in the three items above.

- Data concerning existing code requirements for electrical wiring in residences and the enforcement practices followed with respect to those codes. Identification of mechanisms and usual time intervals required to change these codes and/or procedures.

- Data concerning the training and/or licensing required of electrical workers and electrical contractors, in order to identify expected workmanship and ways of influencing workmanship.

- Data outlining the costs associated with any aluminum wiring hazard, and, in a comparable form, costs associated with proposed ways of reducing the hazard. These costs would need to be identified separately for solutions applying to new housing starts. In addition, it would be essential to be able to assign the costs, e.g., to the consumer, the manufacturer, the builder, the government, society, etc.

3.1.3 Data Required to Describe the Performance of Aluminum Wiring in Residences

The desirability of performing technical field investigations is underscored by limitations inherent in laboratory efforts. Rather strong incentives to minimize the number of variables under laboratory investigation tend to restrict the scope of such investigation to the examination of only a few of the relevant conditions and, therefore, possible interactions of the various characteristics. It is believed that carefully executed study of the interaction of these conditions is necessary, and therefore there exists a requirement for field investigations. The information thus obtained would provide the basis for the definition of the necessarily limited scope of the laboratory studies. 
Detailed description of the performance characteristics of aluminum wiring in situ (as installed in residences) would require carefully designed data collection. The performance characteristics of aluminum as a conductor have been used to identify many variables which may (either singly or in combination) affect the performance of aluminum conductors as installed in residences. The goal of such a data collection would be to describe the conditions underlying a specified level of aluminum wire performance. As in Sections 3.1.1 and 3.1.2, these variables will be discussed generally here. The need for operational definitions must, however, be acknowledged.

The data which are outlined below would be collected for each aluminum wire junction in a defined sample of such junctions. Sets of data would be required both from residences which are known to have experienced failures and from residences which are known to have experienced no failures; (i.e., both "good" and "bad" connections would be sought.)

The following data are required for each junction:

- Environment of the Connection

- Ambient temperature, exposure to heat

- Relative humidity, exposure to humidity

- Exposure to vibration, mechanical shock or movement

- Exposure to air pollution

- Distance from salt water

- $\quad$ Nature of the Conductor

- Size (gauge)

- Type of insulation

- Alloy

- Specific application

- $\quad$ Nature of Wiring Device

- Type (twist connector, receptacle, snap switch, other-specify)

- Connection techniques (binding screw, push-wire)

- Specification (AL-CU, CO/ALR, other-specify)

- What feeding (use)

- Current capacity

- Applied voltage

- Oxidation inhibitor 
- State of the Connection

- Resistance (load \& nonload)

- Corrosion

- Evidence of Creep

- Torque measurements

- Metal or insulation discoloration

- Thermally or mechanically distorted contacts

- Nature of Installation

- Age (date of installation)

- Identification of installer (homeowner, electrician, etc.)

- Applicable code regulations

- Evidence of code violation

- Nature of Electrical System

- Capacity of service box

- Size of service entrance cable

- Line voltages

If faulty components or junctions are detected:

- Nature of Failure

- Creep of conductor

- Corrosion of conductor and/or wiring device

- Mechanical tension in conductor

- Mechanical failure of wiring device

- Inadequate torque on clamping device

- Excessive oxidation of conductor

- Alerting Condition

- Flicker in lights

- Odor, smoke

- Erratic operation of appliances

- Electrical shock

- Noise on radio

- Fire

- Circuit opened by overload protection means. 


\subsection{Characteristics Required of the Data and Data Collection Procedures}

The enumeration of required data in Section 3.1 presupposes that those data be valid and reliable, and represent some defined population. This section of the report, therefore, briefly outlines some of the general indices of validity, reliability, and representativeness that were used in evaluating the existing field data. These qualities can usually be assumed to be present to some degree, so the evaluation consisted of determining the degree to which they were exhibited in the data or the data collection process rather than determining their presence or absence.

The discussion below is not intended as an exhaustive listing of the criteria used. It cites the more important considerations in the evaluation process.

\subsubsection{Definition of Objectives}

Each source of data was examined to determine whether the data had been collected with clear and identifiable objectives. Lack of definitive objectives was often a precursor to more severe deficiencies in the data. Presence of those objectives allowed a more certain framework for the data evaluation. Indications of clear objectives were:

- Definition, prior to data collection, of the population the data were to represent, (e.g., the performance of aluminum wire in a defined set of aluminum wired residences; the opinions of a defined set of electrical inspectors concerning aluminum wire; etc.)

- Enumeration, prior to data collection, of decisions which were to be made based on the data, (e.g., a decision to allow or to ban the use of certain types of connectors with aluminum wire; a decision to begin or not begin laboratory investigation of the performance of aluminum wire; etc.)

- Specification, prior to data collection, of the variables that would be used to answer the primary questions (decisions) toward which the data collection effort was directed, (e.g., relative numbers of failures of certain wiring devices would be used to decide whether certain devices should be banned; numbers of failures of aluminum wire relative to copper wire would be used to decide whether laboratory research would be required; etc.) 


\subsubsection{Sampling Procedures, If Any}

In cases in which the data collection involved sampling there were two important criteria in addition to assessment of the definition of the population:

- Sampling process: An attempt was made to determine whether the sampling procedure was systematic or haphazard and whether the sampling process matched the stated objectives.

- Estimation process: An attempt was made to determine whether the sample had been designed to meet statistically describable levels of confidence.

\subsubsection{Potential Sources of Observation Bias}

There are certain potential sources of bias to any data collection effort which are not directly related to sampling or the definition of objectives. Those most relevant to the present evaluation are discussed below.

\subsubsection{Nonobservation}

It is often the case in field data collection efforts that it is not possible to observe (collect data for) every relevant event. Nonobservation could have relatively little impact on the data if enough is known to assume that the nonobserved events are few in number or are relatively insignificant to the variables in question. There are, however, forms of nonobservation which must be carefully considered:

- Noncoverage: This form of nonobservation can only be assessed in terms of the data requirements. In some cases, systematic noncoverage is desirable, and is, in fact, specified in the definition of the population. Noncoverage which occurs in an uncontrolled manner because of lack of knowledge about the population or because of faulty selection techniques, however, can be a source of severe error unless it is recognized and accounted for. If noncoverage is not discovered before data collection begins, either the definition of the population must be changed, or an attempt must be made to complete the coverage. An example of accidental or haphazard noncoverage would be a data collection effort concerning wiring failures in which the population had been defined as all aluminum-wired residences in a specified area, but in which the only data collected were those failures which came to the attention of the electrical inspector. In this example, the failures (data) that came to the attention of home owners and/or electrical contractors but not electrical inspectors would not be "covered". 
- Nonresponse: Nonresponse occurs when data cannot be obtained from some portion of the defined sample or population; it occurs not because of lack of knowledge of its existence but because of a refusal to supply data or difficulty in obtaining the data, etc. The most important point to be made about nonresponse is the fact that data not collected (nonresponse) cannot be assumed to be similar to the collected data. In cases of high nonresponse, it is essential that an effort be made (outside of the primary data collection effort) to determine how the unobtained data might differ from the collected data.

Nonresponse could be a very important factor in a data collection effort concerning the presence or absence of a phenomenon such as aluminum wiring failures, because reporting the presence of the phenomenon might be perceived as being very important while reporting its absence might be perceived as not at all important.

\subsubsection{Observing and Recording Data}

In addition to defining a population and specifying variables to meet decision criteria, there are other specific factors concerning observation and data recording which must be considered.

- Operational Definition of Variables: Section 3.2.1 described the need for specifying the variables which would answer the questions toward which the data collection effort was directed. This is a necessary but not sufficient requirement. In addition, operational definitions must he supplied for the variables; the variables must be defined such that there is no room for error during data collection because of differences in interpretation of the meanings of terms. Collection of data about the performance of aluminum wiring in the field presents three striking examples of the need for operational definition for variables: "use of aluminum wire", "failure", and "fire". In almost no case were any of these terms given operational definitions. The individuals observing the events were required to impose their own definitions. In some cases, the lack of definition resulted, for example, in combining data in which "fire" meant only those events for which the fire department was called, with data in which "fire" included incidents in which the insulation on a wire, inside a metal box, had melted. 
- Observer Limitations: Sometimes it is necessary to select and train individuals to observe and record data. In other cases, (particularly in surveys) it is more appropriate and/or convenient to ask individuals who already have knowledge of the relevant variables and are already observing the relevant events to make specific observations and record data. It is necessary to be aware of the limitations of such "borrowed" observers. First, such an observer does not necessarily have the same interest in the variables as the organizer of the data collection effort and therefore, the data collection must be made as relevant as possible to the observer. Second, an individual who can provide data about one sort of event may not be able to provide data about other related events. For example, a fire inspector may be able to observe and record fire-related events associated with aluminum wiring, but he may have no way of observing failure-related events associated with aluminum wiring. Third, it is necessary to operationally define the relevant variables even when dealing with knowledgeable observers, for the reasons cited earlier.

- Documentation: It is sometimes necessary to attempt to collect data about events that are assumed to have occurred in the past. In those cases, an attempt is made either to reuse data collected for some other purpose or to rely on the memories of individuals who might have observed the events in the past. When collecting data after the event, an attempt must be made to distinguish between those data based wholly on memory and those based on some sort of still existing documentation. Recollections must be used with caution because they are so easily influenced by intervening events. It is very useful in situations in which no documentation (made at the time of the event) exists, to ask the respondent to indicate how certain he is of his response.

\subsection{Summary}

This section has identified the data required to make determinations about the nature and extent of any hazard associated with the use of aluminum wiring in U.S. residences. This includes (a) data to determine the nature and extent of the use of aluminum wiring in U.S. residences, (b) data to determine the level of risk to consumers associated with the use of aluminum wiring, and (c) data to describe the performance (causes of any hazard) in residential applications. Also described were the characteristics required of the data, i.e., those characteristics which might be used to judge the adequacy of available information and data. 
Section 4 applies these data requirements as criteria for an evaluation of the information that the study team was able to locate and obtain. Section 5 discusses a general approach to a supplemental data collection effort based on these data requirements.

\section{Field Data and Data Sources Examined}

\subsection{Approach}

An attempt was made to identify any data that already existed concerning the performance of aluminum wiring installed in the field (as opposed to laboratory data). Data which were identified and obtained were evaluated in terms of the data requirements and data characteristics cited in Section 3 in order to determine (a) the possible uses which could be made of existing data, and (b) the limitations of the existing data and the data sources.

This information search involved attempts to contact all types of organizations and officials which were directly or indirectly concerned with the use of aluminum electrical wiring. The first to be contacted were those already known or suspected to have experience in this area. Subsequent contacts were based on referrals from earlier contacts or citations in documents. This process was continued until virtually all of the new referrals were to sources already contacted. Many of the contacts were fruitless. Those that showed some promise were probed more thoroughly to check the validity of the data and evaluate their usefulness. The findings are detailed in section 4.3.

The organizations and officials contacted are listed below in six groups. The list includes four additional contacts in the Washington, D.C., area that were made by the CPSC but that did not warrant additional followup.

Research Organizations (Other than NBS and CPSC)

Battelle Memorial Institute

Johns Hopkins University Applied Physics Laboratory

National Fire Protection Association

Underwriters' Laboratories, Inc.

Insurance Organizations

American Insurance Association (formerly National Board of Fire Underwriters)

American Plan Corporation (insurers)

General Adjustment Bureau (insurance investigators)

Insurance Services Office

National Association of Mutual Insurance Companies

Value Engineering Laboratories (insurance investigators) 


\section{Fire Officials}

Fire Inspector (Electrical), Huntington Beach, California

Fire Inspector (E1ectrica1), Washington, D. C.

Fire Marsha1s:

Fairfax Co., Virginia

Montgomery Co., Maryland

Maryland (state)

Orange Co., California

Prince William Co., Virginia*

International Association of Fire Chiefs

Internationa1 Association of Fire Fighters

\section{Electrica1 Inspectors}

Chief Electrical Inspectors:

Baltimore Co., Maryland

Fairfax Co., Virginia

Frederick Co., Maryland

Idaho (state)

Montgomery Co. , Maryland

North Dakota (State Electrical Board)

Prince George's Co., Maryland

Prince William Co., Virginia*

Providence, Rhode Island

Washington, D. C.

Internationa1 Association of Electrical Inspectors

Middle Department Inspection Agency (contract organization in the mid-Atlantic states that serves as electrical inspector for jurisdictions not directly employing their own inspectors)

\section{Electrical Manufacturers}

Alcoa Conductor Products

Aluminum Association

Copper Development Association

General Electric Company, Wire and Cable Division

*ontacted by CPSC 


\section{Builders and Electrical Contractors}

$\mathrm{B}$ and $\mathrm{H}$ Electric (contractor in Virginia)

Continental Corporation (contractor in Virginia)*

General Services Administration (U. S. Government)

International Brotherhood of Electrical Workers

Kettler Brothers (builder in Maryland)*

Marriott Corporation (hotel and restaurant chain)

Master Electricians' Association of the National Capital Area

Minchew Corporation (builder in Virginia)

National Association of Home Builders

National Constructors Association

National Electrical Contractors Association

\subsection{Summary of Data Sources Examined and Their Limitations}

\subsubsection{Systematic Documentation}

The primary obstacle to deriving information from these sources with respect to the hazards associated with aluminum wire is the fact that there has been relatively little interest in the field in documenting the extent of the hazard, once its existence was accepted. Most organizations and officials, if they felt a hazard existed, focused their attention on eliminating or reducing the hazard. It was generally thought by these sources to be unnecessary to undertake extensive documentation, since the perceived existence of a threat to public safety was sufficient to justify corrective action. NBS has found a generally uncritical acceptance of the judgment that a serious hazard exists, and it is impossible to determine to what extent this judgment has been based on anecdotal reports, opinions and restrictive actions of others, rather than on direct experience. There are a few exceptions to the general lack of interest in documenting the extent of the hazard, and the information that may be derived from them is included in section 4.3 .

There is however, a sharp distinction between the documentation needs of fire marshals and electrical inspectors, on the one hand, and the documentation required in this study, on the other hand, to demonstrate statistically the existence of a hazard and to develop a statistically sound estimate of its magnitude. Due to these differing needs, it is neither surprising nor an adverse reflection on the sources that the existing data are insufficient for the purposes of this study. In the former case, a reasonable degree of suspicion of hazard is sufficient to warrant a response of caution in the name of public safety until the matter can be cleared up.

* Contacted by CPSC 
In the latter case it is necessary to have actual numbers of fires or failures, in order to calculate fire or failure rates with respect to exposure. Exposure represents (a) a measured population of installations among which failures potentially could occur, and (b) a definite period of time, sufficiently long to average over random fluctuations.

There are at least four concepts of fire or failure that are important in establishing an estimate of hazard in this study. One is simply failure, defined as any condition of the electrical system that prevents it from performing as intended. Second is fire without structural damage, defined as a condition where some form of combustion is caused by a malfunction. Third is fire with structural damage, defined as destructive burning of structural components, caused by an electrical system malfunction. Fourth is shock hazard, which for the present discussion may remain undefined. Of the first three, the third is clearly the most important from the standpoint of hazard estimation. A structural fire is clearly a hazard to life and limb, whereas any number of circuit failures or of fires confined within receptacle boxes may present no hazard at all.

\subsubsection{Fire Investigations}

Fires have been investigated by insurance organizations, fire inspectors and electrical inspectors, but the investigations have been generally confined to cases having a particular interest, such as loss of life, heavy financial loss, suspected arson, or lawsuit. These investigations normally cover neither the totality of electrical fires nor a representative cross section. A further inadequacy of the records of these investigations, for the purpose of this study, is that they generally contain only broad categories of cause (e.g., "electrical"). The kind of wire and the kind of device or connector are generally not recorded, since, until recently, there was no interest in such detail. Some insurance records identify only the class of structure and general location, not the cause of the fire. Statistics on fires attributed to electrical causes may also be contaminated by two other factors, according to these sources. First, most fire departments do not have fire investigators who are also trained or experienced in electrical matters. Reportedly, only two fire departments in the U.S. have a fire investigator who is also a master electrician, and many fire departments have no trained investigators specifically for electrical fires. (19) Thus, it is commonly accepted that some of the fires identified as electrical did involve some piece of electrical equipment, but not necessarily as a cause. Second, it is reported by these sources that fires of unknown origin are sometimes called electrical and that investigation reports are sometimes written without an on-the-scene investigation having actually taken place. 


\subsubsection{Incomplete Reporting of Electrical Failures}

When a homeowner experiences electrical system malfunctions, but not fire, he is most likely either to attempt a repair himself or to call an electrician (perhaps the contractor who installed the faulty component); these cases rarely come to the attention of the fire and electrical inspectors.

\subsubsection{Biases}

Builders and electrical contractors being interviewed with regard to hazardous conditions involving products installed by them have a natural incentive to be less than candid. On the part of inspectors and others, perceptions of individual cases and recollections of groups of cases are necessarily preconditioned by opinions based on their own prior experiences and on the reports of others. Thus, once an inspector has formed the opinion that aluminum wiring is a fire hazard, the mere presence of aluminum wiring at the scene of a fire may induce him to attribute the fire to that wiring. Furthermore, when asked to estimate numbers of fires caused by aluminum wiring he may overestimate the number and/or include all the incidents that he perceives to have potential fire conditions.

\subsection{Sumnary and Evaluation of Information Found}

The information compiled from the sources identified must be presented as an informal summary of what these people perceive and believe, since it does not represent a formal survey. It does not establish the existence of a hazard nor does it provide a measure of such a hazard.

\subsubsection{General}

Virtually all of the persons contacted by NBS were aware that there is alleged to be a problem with the use of aluminum for electrical wiring. Virtually all believed that in fact there is, or has been, such a problem. All of these agreed that failures occur principally at terminations; occasional failures have occurred elsewhere along the wire.

Most of the people contacted believed that the chemical and physical phenomena relating to this problem are well understood, and felt that they themselves understood the important phenomena. (It may be remarked here that the laboratories engaged in studies of this problem are in some doubt about those phenomena.) Accordingly, many of these people believe that with present knowledge it is possible to use aluminum wiring without creating hazards. Some of them claim that their own experience with the use of aluminum wiring has been essentially trouble-free, and they attribute this to their precautionary measures. 
An example is Fairfax County, Virginia, where some aluminum wiring has been used but reportedly with no more trouble than with copper wiring. The Fairfax County electrical inspector attributed their lack of problems to stringent workmanship requirements and a more intensive inspection schedule when aluminum wiring was used. (20) Fairfax County is a notable example for its contrast to Prince George's County, Maryland, which is in the same geographical area and which has reported considerable difficulty with aluminum wiring (discussed in Section 4.3.2). It should be noted that jurisdictions using aluminum wiring without significant numbers of problems have little or no incentive to keep fire or failure records which separately identify aluminum installations. Therefore, it is unlikely that any widespread trouble-free use of aluminum has been documented.

A broad variety of diagnoses and recommendations were voiced by those contacted, and few recognized this lack of agreement. Some recommended more than one of these measures.

In 1969 the San Mateo County (California) Chapter of the National Electrical Contractors Association solicited information from several cities regarding the use of nonmetallic-sheathed cable, and some of the replies included remarks pertinent to aluminum conductors. In 1971 both the NBS Office of Fire Research and Safety and the Fire Inspector (Electrical) of Huntington Beach, California, queried fire officials to determine whether there was evidence from the field that aluminum wiring had been responsible for fires. These efforts elicited a broad variety of responses. Since there was no attempt to design the sampling procedure to be nationally representative with respect to various demographic factors, and since their objectives were dissimilar, an enumeration of the responses by type would be misleading. Nevertheless, the following excerpts illustrate the wide variety of perceptions and experiences with aluminum wiring that existed at that time and that continue to exist now.

"We have found that a properly installed job of copper or aluminum non-metallic cable is a very safe and trouble-free wiring job."

"We have had no fires which have been attributed to the use of aluminum wiring."

"Our records do not reflect any increase of fires caused by aluminum wiring, over those resulting from conventional copper wire."

"Experience is not sufficient here at this time to determine if aluminum used in electrical wiring is creating any problems."

'We show approximately 230 fires originating from wiring but no designation whether it was copper or aluminum." 
'We have been aware of the possible fire hazard involved and have expended considerable time and effort to determine whether or not any action should be taken to curb or control its use. There have been very few fires involving aluminum wire. All the fires were investigated and found to be caused by code violation or faulty workmanship."

"We cannot attribute any structural fire damage to the use of aluminum used in the wiring systems. We can report smoke damage resulting from fire damage in switchboards."

"A survey of our fire records for approximately three years indicates only one apparent response to a fire of this type; this causing damage only to the outlet. However, several calls have been received regarding the cause of arcing, smoking or fire coming from electrical outlets some time after the occurrence."

"One serious fire occurred as the result of an electrical short at a convenience outlet in a two story home. The fire caused $\$ 10,000$ damage. A contributing factor to the extensive damage was the absence of a fire block at the roof line."

"We have had problems on joints where a combination of copper and aluminum terminated and the wrong type connector was used. We have had fires where aluminum cable was used on quick-wire receptacles."

"We have run into more than one condition on size six and larger aluminum cable where it has broken down and blown up at the point where it enters a pane1. A proper connection was used in all cases. We concluded that it was the fault of the cable, in that it will not take any abuse or strain where it passes through the connector."

"In recent months, we have had several dwelling fires which involved aluminum wiring. The resultant fire damage has varied from the cost of replacing a convenience outlet to $\$ 3,000.00$. To date, there have been ten of these fires reported to our department. We feel certain that there have been other incidents which have not been reported."

Probably the most significant fact to emerge from contacting these sources is that most of these people believe not only that they understand the problem and its solution, but also that there is a general consensus on the matter. 


\subsubsection{Specific Sources of Information}

Several of the sources identified had particular potential as sources of information about the performance of aluminum wiring in the field. These sources met one or more of the following three conditions: they were frequently cited by others; (b) they were known to have made a special effort to document fires and/or failures associated with aluminum wiring; (c) they had taken formal action to restrict the use of aluminum wiring prior to UL's announcement (July 1971) that as of September 1, 1971, devices formerly approved for use with aluminum would no longer be approved. These potentially important sources were individually contacted, and in the following paragraphs the information obtained from each source is briefly summarized and assessed with respect to its value as a basis for determining the extent of hazard attributable to aluminum wiring.

\subsubsection{Consumer Product Safety Commission}

The CPSC has undertaken four efforts relating to such documentation: (a) the National Electronic Injury Surveillance System (NEISS) data bank, (b) a brief "survey" of data available from jurisdictions in the Washington, D. C., area, (c) a follow-up of some respondents to the 1972 UL survey, and (d) a continuation of the NBS data collection described in this chapter.

The NEISS data bank has a product class (0605) representing electrical outlets, built-in wiring devices and distribution systems. The file contains in-depth investigatory reports for 65 accidents in this class, the earliest occurring in December 1965 and the latest in December 1973. In 44 of the 65 cases, the type of conductor (aluminum or copper) was clearly irrelevant; examples of attributed causes are "inserted bobby pin in outlet" and "grasped electrically charged wires." In the other 21 cases it is impossible to determine whether the type of conductor was relevant, and the type of metal used is not stated; examples of attributed causes in this group are fuse box "exploded," short in receptacle, and faulty wiring.

The CPSC staff forwarded to NBS a report of another accident in which there was a fire resulting in a death (although the report indicated some doubt that the death was a necessary consequence). In this case the fire department at the scene attributed the fire to a failure of aluminum wire.

The local CPSC survey found no records relating to aluminum wiring failures other than those found in the NBS investigation, summarized below in section 4.3.2.6.

In March 1974, the Los Angeles field office of the CPSC attempted to contact six jurisdictions in California that had reported aluminum-wirerelated fires in the 1972 UL survey. The field office was successful in obtaining written records from three jurisdictions. The records are reports of individual incidents and do not represent complete coverage 
of a statistically definable sample. For that reason and because these reports are not based on consistent definitions of "fire" and other important terms, they provide only anecdotal information rather than statistical data.

Since the NBS data collection and evaluation (project phase I) was completed (June 1974), the CPSC has continued to collect reports of incidents that have come to their attention.

\subsubsection{Underwriters' Laboratories, Inc. Field Surveys}

In 1969 , subsequent to receiving reports of problems in the field with aluminum wiring, UL and the National Electrical Manufacturers Association (NEMA) conducted a survey to attempt to explore the performance of aluminum wiring in the field. In 1972, UL conducted another survey to evaluate the field performance of aluminum conductors in branch circuits. In 1974, UL administered follow-up questionnaires to a number of the respondents to the 1972 survey. This section discusses the data and data collection procedures of these three efforts.

\section{UL/NEMA Survey}

In 1969, UL and NEMA conducted a survey as part of a "Fact-Finding Study, Terminations for Aluminum Conductors in Electrical Distribution Equipment". A statement from a report of its results -." ... there is statistically a failure rate of approximately 7 to 1 of aluminum over copper." (21) -- has apparently become the source for a number of publicly available pronouncements:

'Underwriters' Laboratories found in comparison, homes constructed with aluminum wiring were seven times more likely to have a fire." (22)

"One estimate has placed the present failure rate of aluminum terminations as at least 7 to 10 times the rate for copper in applications below 100 to 200 amperes." (23)

If the presumed relationship between the UL report and these statements exists -- and there appears to be no alternative source for these statements - - this early UL/NEMA survey takes on great significance.

The following evaluation shows that the survey provides no acceptable basis for the original statement (and, therefore, the re-reported statements) and will, it is hoped, prevent its data from being used as evidence of the numbers of aluminum failures relative to copper failures. 
According to the UL/NEMA report, approximately 12,500 questionnaires were distributed by mail: 1,000 were sent to (unspecified) industrial users of electrical equipment, and about 11,500 were sent to electrical inspectors and electrical contractors identified simply "... through connections with the National Electrical Contractors Association and the international Association of Electrical Inspectors." (24) The survey had an extremely low response rate (See 3.2.3.1). Only 13.5\% of the 11,500 electrical inspectors/electrical contractors returned questionnaires and about $17 \%$ of the industrial users returned questionnaires. The UL/NEMA report does not discuss the implications of the response rate, nor does it cite any efforts to determine why it occurred or whether nonrespondents might differ from respondents in terms of the relevant variables - - rates of failures associated with aluminum and copper wiring. The low rate of response, since there was no determination of its possible effect on the data, is sufficient in itself to render any analytical treatment of the data useless. The most that could be reported from these data would be "those who responded said ..."; certainly it is not possible to make any assumptions that these data are representative of any populations.

Beyond the matter of representativeness, there would still be major questions concerning the validity of these data. The survey questions were, in some cases, ambiguous. Concern for internal validity can perhaps best be summarized by the report's author:
"In looking at the answers received as a whole, it is apparent, because of the differences in percentages involved in questions which seem to supply in general the same information, that either the persons to whom the questions were directed did not understand what was being asked, or there was not sufficient care taken in making the replies." (25)

The data collected from this survey should be used only as a collection of anecdotal accounts from the field. As such it demonstrates some thinking by individuals experienced with aluminum wiring. It is most unfortunate that these data were analyzed and the resulting observations reported as they were.

\section{UL Survey}

In December of 1972, UL mailed questionnaires to approximately 1,100 chief electrical inspectors, members of the International Association of Electrical Inspectors (IAEI). The questionnaire was designed to get field information about the use and performance of aluminum wire terminations at snap switches and receptacles between 1962 and 1972 . The questions were specifically concerned with terminations of aluminum conductors at wire binding screws and to copper pigtails. $(26,27)$ The evaluation below will show that although the data from this survey provide useful descriptions of the perceptions of some electrical inspectors concerning the performance of aluminum wire, these data cannot be pro- 
jected to estimate the level of risk to the consumer associated with the use of aluminum wire.

The reports of this survey and the 466 returned questionnaires were carefully examined because this survey was regarded as the most promising source of data to perform the estimation of hazard. Unfortunately, these data have deficiencies which preclude their use for this purpose. The most important of these are discussed below.

Population: It is known that not all individuals with local responsibility for electrical inspection are members of the IAEI. Although a vice president of the IAEI estimates that approximately $80 \%$ of the chief electrical inspectors in the U. S. are members of the IAEI, (28) no other source was even willing to guess at the total number of independent electrical inspection jurisdictions that exist in this country. Therefore, the population for this survey must be defined specifically as all chief electrical inspectors who are members of the IAEI, not all electrical inspection jurisdictions in the U. S. (It should be noted that a few of the respondents to this survey were from Canada and the Virgin Islands, etc., and these responses were not separated from U. S. responses in the tabular reports.)

- Response Rate: 466 of the 1,100 chief electrical inspectors returned questionnaires, for a response rate of about $42 \%$. (29) The UL project leader stated that 10 of the nonrespondents had been contacted by telephone and that their lack of response was reported to be caused by "... lack of interest, which was explained as little or no experience with aluminum conductors." (30) A small telephone validation survey was conducted by NBS. Twenty-five of the nonrespondents were selected randomly and were contacted with the following results: (a) A11 25 jurisdictions had allowed aluminum wiring to be used during some part of the 10 year interval, in 23 of the 25 jurisdictions at least some homes or apartments had been wired with aluminum during that period, and 4 of the 25 said that "thousands" of aluminum wired homes or apartments had been built during that period. (b) of the 23 jurisdictions which reported aluminum wired residences built in that time interval, 19 said that at least some of the residences had aluminum branch circuits. (A1though they were not questioned specifically about aluminum wiring problems, some respondents did volunteer that they had had problems, that they did not like aluminum wiring, or that they had had no problems.) 
The NBS validation survey shows that it is not possible to support the assumption that nonrespondents had "little or no experience with aluminum conductors", but this brief survey is not sufficient in itself to show exactly how the data from the UL survey might have been affected by the low response rate.

- Consistency: Lack of consistency in wording some of the major questions in the questionnaire prevents comparison even of responses supplied by a single respondent. The following three questions are the primary occurrence of this lack of consistency (emphasis ours):

"1. Have building or electrical codes in your jurisdiction allowed the use of aluminum wiring at any time in the last 10 years?"

"4. Has direct termination of aluminum wire to binding head screws of snap switches and receptacles been allowed in your jurisdiction at any time during the last 10 years?"

"13. Have copper pigtails been used in your jurisdiction at any time during the last 10 years as a means for terminating aluminum branch circuit conductors in switch boxes and receptacle outlets?"

It is not possible to compare Questions 1 and 4 directly with Question 13, because in the first two questions the word "allowed" is used while in the last question the word "used" appears. Comments written on returned questionnaires and statements made during the NBS nonrespondent survey indicated that many more respondents said aluminum was allowed than said it was used.

- Interpretation: No definitions were supplied for "failure", "fire", or "occupancy", etc. (See Section 3.2) There is no way to determine what definitions were used by the respondent and how the numbers reported were determined. The lack of operational definitions throughout the questionnaire demands that caution be used even in making statement such as "There were at least... reported fires."

Reliability: Although the questionnaire and covering letter for the survey both clearly stated that information was required for terminations of aluminum conductors at snap switches and receptacles, (which implies branch circuit wiring), some respondents explicitly indicated that their answers incorporated information on service entrance 
cable and/or appliance circuits as well. Inclusion of these responses contaminates the stated meaning of the data; it also creates uncertainties concerning the possibility of their implicit inclusion by other respondents.

- Accuracy: The numerical values supplied by respondents were usually their best estimates. The variability in accuracy cannot be ascertained, a1though it is known that the numbers of failures and fires supplied ranged from approximate percentages of numbers of aluminum wired homes (e.g., 10\% of tota1); to a linear extrapolation of 18 months of data to an estimate for ten years; to actual numbers observed.* UL follow-up contacts with some of the respondents indicated that almost all of the answers were based on impressions and memory rather than systematically-kept historical records.

Thus, although it would probably be possible to overcome the limitations imposed on the results by nonresponse, the other deficiencies of the data resulting from the many limitations of the survey instrument do not recommend such an effort. Under these circumstances, the survey data must be confined, as with the earlier 1969 UL survey, to use only as a fertile source for anecdotal information of varying quality and utility.

\section{UL Survey}

In January 1974, UL mailed a follow-up questionnaire to each of the 53 jurisdictions that had reported at least one aluminum associated fire in response to the 1972 questionnaire. Despite intensive follow-up by UL, only 30 questionnaires were returned. Due to the deficiencies of the 1972 survey on which this survey was predicated, only anecdotal information can be validly derived from this survey. Notes included by the respondents to this survey indicated that "the answers to the original questionnaires were incorrect in a great many cases, and that reported fires at receptacles were caused by other factors than poor aluminum wiring terminations." (32)

\subsubsection{American P1an Corporation}

The Wa11 Street Journal reported in September, 1972, that American P1an Corporation, an insurer of automobiles and mobile homes, intended to stop writing coverage on mobile homes equipped with a aluminum wiring, because a study revealed a "suspiciously large number" of fires in such homes. (33) A company official (34) indicated the company "no longer felt that conclusions drawn at that time were sufficiently significant

* The most extreme response, a report of 100 fires in Prince George's County, Maryland, is given explicit attention below (4.3.2.6). 
to require a distinction between aluminum and copper wiring." Thus, contrary to the impression given by the article, this is not a source of data on aluminum wiring failures.

\subsubsection{International Association of Electrical Inspectors}

The International Association of Electrical Inspectors (IAEI) makes an annual tabulation of electrical fires and accidents. This is based on a survey of approximately 1,100 association members who are chief electrical inspectors in their respective jurisdictions. The survey identifies various types of appliances, cables, distribution panels, lighting fixtures, receptacles, switches, terminations and splices, etc. For each category, the form asks for the number of electrical accidents in three sub-categories: shock, fatality and fire (no definitions are supplied for the categories or the subcategories). Only in the "terminations and splices" category is a distinction made between copper and aluminum conductors. The IAEI tabulation provides no means of inferring an accident rate, i.e., no means of rating the number of accidents reported to the total number of copper or aluminum terminations (for example) in use. Conceivably, numbers of terminations in use might be obtained from individual jurisdictions represented in the survey responses. Also, the totals of accidents reported may be useful as evidence of hazards, if a survey follow-up is undertaken to determine the validity of the reports. In the most recent survey (reporting accidents in 1973) 227 responses were received, making a response rate of about $20 \%$. As discussed above in connection with the 1969 UL survey, a response rate this low precludes any valid analysis of the results. No follow-up of the respondents nor of the nonrespondents has been attempted. The survey has not been used as a basis for any analysis, and the published tabulation (35) cautions against using the information for comparing one material with another.

\subsubsection{National Fire Protection Association}

The National Fire Protection Association (NFPA) has recently polled over 800 fire marshals at the state and local levels. Only in the case of mobile homes, trailers and recreational vehicles did the survey ask for aluminum wire to be identified. This data collection effort had a case history format rather than a tabulation format (such as the IAEI and UL surveys), and thus does not provide a basis for calculating failure rates. Furthermore, only 32 responses were received.

\subsubsection{Prince George's County, Maryland}

The chief electrical inspector of Prince George's County, Maryland, maintains a special file which documents incidents involving aluminum wiring. This file, which was begun in July 1971 was provided to NBS in March 1974 and was found to contain records of 17 such incidents, four of which were fires resulting in structural damage. The 1ocal CPSC survey identified eight fires in this file. Their reporting of four additional fires is apparently to be explained as follows: Three were 
fires that did not involve structural damage (one in a distribution panel and two in outlets), and one represents a call to the fire department due to a short circuit in an outlet but where there was no damage to the structure.

The figure of 100 fires reported for Prince George's County in the 1972 UL survey was reportedly derived as follows. (36) At the end of 1972, the file contained 11 incidents which had occurred in an 18-month interval. All of these incidents were considered to be potential (if not actual) fires. In addition, it was known that complaints had been received which were not added to the file. On this basis the chief electrical inspector estimated a rate of ten fires per year. Since the UL survey asked for the number of fires in ten years, an estimate of 100 fires was supplied.

\subsubsection{Washington, DC}

The Fire Inspector (Electrical for Washington, DC, has taken an active interest in problems associated with aluminum conductors for the past several years. However, due to the nature of new construction in Washington in recent years, aluminum conductors employed there are almost exclusively busbars in office buildings, rather than wiring in the sizes found in houses. There are only four or five aluminum-wired houses in the city, and all branch-circuit wiring in large buildings is copper. (37) Residential applications could potentially include high rise buildings where such busbars might be used, and the explosion and toxic gas effects observed in office buildings could pose a threat to civilians as well as firefighters.

\subsubsection{Huntington Beach, California}

The Fire Inspector (Electrical) of Huntington Beach, California, has also kept records relating specifically to incidents involving aluminum wiring. In the period May 1970 through August 1971 there were four fires attributed to aluminum wiring that caused structural damage, one of which caused a death. (38)

\subsubsection{Summary}

If accurate estimates of the numbers of aluminum installations can be obtained for Prince George's County, DC, Huntington Beach, and IAEI respondents then estimates could be developed for the rates of fires with structural damage. However, the estimates are likely to be very rough -- perhaps useless -- because of the rarity of the phenomenon and possibly also due to incomplete or inconsistant record-keeping.

Estimating the number of fires in an extended period - say, ten years - on the basis of fires occurring in a shorter period involves several assumptions or adjustments. First, it must be assumed that the observed fire rate (e.g., fires per thousand homes per year) is the true 
fire rate over the entire ten-year period. Second, the estimate must be adjusted to correspond to the numbers of houses at different times within the ten-year period. Third, it should be based on the number of actual fires that have occurred. Any estimate that may be derived necessarily depends very much on these considerations.

This can be illustrated by using the Prince George's County data for the 18 months ending December 1972; among the 11 incidents there had been seven fires, four of which resulted in structural damage. Assuming that the aluminum-wire homes were built at a constant rate throughout the ten-year period (and starting at the beginning of that period)* and assuming aconstant fire rate (fires per thousand homes per year), the estimated total number of àctual fires in that ten-year period would be 25 , and the estimated number of these fires with structural damage would be 14 . Using all of the data in the Prince George's County file up to the time when the file was examined in the course of this study, there have still been only the same seven fires, four with structural damage, during a period of 32 months (July 1971 through February 1974). This results in ten-year estimated of 14 actual fires, 8 of which caused structural damage. It should be clear from these examples that the necessary assumptions and the rarity of the phenomenon make rate estimates somewhat arbitrary and rather unreliable.

The foregoing discussions clearly show that the field data, as they now exist, are insufficient for establishing a rigorous statistical hazard estimate. It is conceivable, however, that some of the extant data could be used in conjunction with data derived from a new data collection effort designed around the needs of this study. (See Section 5 for a discussion of a data collection undertaking.)

Clearly, reports of problems with aluminum wiring have caused UL and affected industries to respond (See Section 2), and either direct experience or reported experience has convinced some state and local officials that there was or is a sufficient problem (or sufficient possibility of a problem) that they should take actions to restrict the use of aluminum wiring. These actions are discussed in the following section.

\subsection{State and Local Restrictions on the Use of Aluminum Wiring}

Numerous state and local jurisdictions have placed restrictions on the use of aluminum for residential wiring. A review of these restrictions provides some indication of the climate of opinion about aluminum wiring problems. Of greater interest is the basis on which each action was taken -- e.g., actual experiences of problems within the jurisdiction, or the recommendations of other jurisdictions or UL -- as this information not only provides a clue to potential sources of data, but also

\footnotetext{
*As reported by Mr. Kuntz. (39)
} 
indicates the extent to which a judgment by one authority may be reflected in the actions of others.

The restrictive actions that have come to our attention are listed in this section. The list must be regarded as incomplete. The actions have been identified through a miscellany of sources: the Aluminum Association, copies of notices to contractors, newspaper articles, personal knowledge, etc. In many cases the source information was fragmentary (and occasionally contradictory), and to date most of the jurisdictions involved have not been contacted for confirmation and updating of the reported information. The purpose of the list is only to indicate the variety of restrictive actions that have taken place. A thorough survey of restrictions would be an extensive undertaking in itself. Section 5 discusses a plan for such a survey.

Ordinarily one might not consider as a restriction the simple requirement that only UL-listed components be used. However, in July 1971 UL withdrew their approval, effective September 1, of all then available devices for use with aluminum wire and established a new approval program for such devices, and in the preceding month UL had initiated new requirements for their approval of aluminum electrical wire. For nearly a year in the case of devices, and for more than a year in the case of wire, no such components were approved by UL. Thus, during this period, a state or local requirement that all components used be listed by UL amounted to a prohibition of aluminum wiring. This requirement remained a "restriction" for some time afterward as few devices and wires gained approval and became available. For this reason, the following list of restrictive actions includes some overt notices by state and local authorities, following the change in UL requirements, stating that electrical components in aluminum wiring applications must be listed for that application by UL.

The list provides scanty clues as to the bases for the restrictive actions undertaken. In at least five cases the restriction was imposed prior to UL's July 1971 announcement. There was, however, a series of meetings and correspondence between UL and several other parties prior to July 1971; at least some of these five jurisdictions were included. Therefore, the experiences of these jurisdictions may have been part of the basis for the UL action. Of the other 26 jurisdictions in the list, there is evidence that at least 10 were responding to the UL action. Of course, this does not preclude their having had independent basis for action. In at least one case (the Texas State Building Commission) the restriction on aluminum wiring was part of a ban motivated by a failure of a bus system in a large building rather than by failures of branch circuit wiring.

Although it is impossible to determine from presently available information exactly how much independent basis there has been for restrictive actions, it is clear that some jurisdictions have had an independent basis and that some actions were based on the experiences of others. Even though of somewhat questionable validity, a survey of electrical 
This list must be regarded as incomplete and tentative, as explained in the text.

\section{Place}

Arizona

Tucson
Effective date

$12 / 21 / 71 *$
Latest date known to be in effect

$11 / 9 / 73$
Type of restrictions

\section{* California \\ Huntington Beach 9/3/70 \\ Los Angeles $\quad 11 / 1 / 71$ \\ * Orange County $12 / 70 \& 1 / 71$ \\ (9 jurisdictions) \\ Sacramento \\ $12 / 1 / 71$}

District of Columbia $1 / 7 / 72$ present

$2 / 1 / 72$

present
Bans Al nonmetallicsheathed wire for branch circuits

Bans Al wire Requires UL approval or devices

Bans Al \#6 and smaller

Requires UL approval of devices

Bans the old wire alloys Bans AL-CU devices unless body of conrector is aluminum

Bans Al wire

Bans Al \#8 \& smaller

Bans Al smaller than \#8

Pigtails required unless UL-approved devices are used.

Requires UL approval of devices

Kentucky

Lexington \&

Fayette Counties $4 / 1 / 72$

$11 / 9 / 73$

Louisiana

Baton Rouge

Ban lifted in 1973

However, UL approval of devices is now required

* Asterisk indicates the earliest date known, from present information, to be in effect.

**

Double asterisk marks restrictions known to antedate UL's July 1971 announcement. 
Place

Maryland

Baltimore Co. $\quad 1 / 1 / 72$

Montgomery Co. 5/26/72

Pr. George's Co. 3/1/72

Michigan

Dearborn

Mississippi

Jackson area

$9 / 6 / 73$

Nevada

New York

(a) $2 / 1 / 72$

(b) $7 / 1 / 72$

* North Dakota

1968

Ohio

Cincinnati

$5 / 1 / 73$

**Rhode Island

Providence

Scuth Carolina

Myrtle Beach

Approx. 1965

$2 / 29 / 72$

Tennessee

Murfreesboro, Jan. 1972*

Lebanon, Franklin,

Woodbury

Texas

State Building

Commission

$1 / 12 / 72$

Arlington

$4 / 1 / 72$

Houston

Richardson

$2 / 14 / 72$

Garland, Plano,

$9 / 1 / 73$

Farmers Branch,

Lewisville,

Carroleton, Mesquite

Virginia

Arlington County 2/7/72

Washington

$9 / 1 / 71$ present

present

$11 / 9 / 73$

$11 / 9 / 73$

$11 / 9 / 73$

$11 / 9 / 73$

1970

$11 / 9 / 73$

present

Ban lifted

$3 / 7 / 72$

Ban lifted in 173

$11 / 9 / 73$

$10 / 4 / 73$
Type of

restrictions

Requires pigtails or UL approval of devices Bans Al \#6 and smaller Bans Al \#6 and smaller

Bans Al \#10 and 12

Bans $\mathrm{Al}$ in FHA-insured and HUD-financed housing

Bans Al in mobile homes, except grounds and lead-ins

(a) Requires pigtail on \#10

(b) Requires pigtail on \#12

Banned Al wire

Requires pigtails

Bans Al smaller than \#6

Bans Al wire

Bans Al smaller than \#6

Banned Al wire

Requires UL approval of devices

However, UL approval of devices is now required

Requires UL approval

of devices

Ban Al branch

circuit wire

in dwellings

Bans Al wire

Requires pigtails 
inspectors conducted in September 1971 by the Information Gathering Service of Harvard Student Agencies, Inc., lends some support to the impression that the UL announcement in July 1971 had a large influence. The survey cited that UL announcement and asked whether the respondent intended to require contractors using aluminum in branch circuit installations to use only wiring devices approved by UL for that use. Although only 501 of the 2,000 electrical inspectors replied to the questionnaire, 407 of the respondents said that they intended to require UL approved devices for aluminum and an additional 63 inspectors said that they had already prohibited or severely restricted the use of aluminum in branch circuit installations.

\subsection{Estimated Numbers of Homes with Aluminum Wiring}

One aspect of estimating the level of hazard associated with aluminum wiring is the number of homes (including apartments and mobile homes) having such wiring. A home may have aluminum wiring throughout, or only in a recent addition or recently rewired section, or only at the service entrance. There are no records of the number of such homes in the nation. An order-of-magnitude estimate has been made of the number of homes wired entirely with aluminum, but there is no basis for estimating the number of homes wired partly with aluminum. It is known that current home construction predominantly uses service entrance wiring of aluminum.

The order-of-magnitude estimate was derived by dividing the amount of aluminum wire produced from 1960 through 1971 by a quantity representing the amount of wire per home. Only a very approximate estimate can result from this procedure, both because the wire production data are estimates subject to error and especially because a single number used to represent the average wire content of a home is necessarily a rough approximation.

The production data (in millions of feet of cable) were provided by the Aluminum Association in 1972 and are based on a survey of their members (40) They are presented here along with their equivalent in millions of meters.

\begin{tabular}{lcc} 
Year & Millions of Feet & Millions of Meters \\
\cline { 2 - 3 } & 77 & 23 \\
$60-1965$ & 119 & 36 \\
1966 & 192 & 59 \\
1967 & 349 & 106 \\
1968 & 419 & 128 \\
1969 & 569 & 173 \\
1970 & 771 & 235 \\
1971 & &
\end{tabular}

These figures represent an aggregate of wire sizes; the Association was not able to make estimates for individual wire sizes. These may be taken as representative of housewiring sizes. The Association members supplying the raw data from which these estimates were derived ordinarily reported production quantities by weight rather than length. Consequently, it was 
necessary for the Association to convert from weight to length, and this contributed some uncertainty to the estimate since a single conversion: factor was applied to a conglomeration of wire sizes.

In 1972 a number of aluminum-wired homes was estimated at NBS, based on the wiring required for an average three-bedroom house. The resulting estimate was 1.5 million homes. This estimate was obtained in such a way that 1.5 million homes is conservative and the actual number of houses is probably higher than $1.5 \mathrm{mi} 11$ ion.

The Aluminum Association estimated that the 1970 wire production was enough to wire about 450,000 homes. (41) Applying this relation to the production data for 1960-1971, the estimated number of homes wired with aluminum is 2.0 million.

More recently a new estimate was derived at NBS from the same production data with a somewhat different approach to the amount of wire per home. Data compiled by the National Association of Home Builders, (42) representing six sizes of houses, indicated an (unweighted) average of 0.86 feet of wire per square foot of floorspace. An estimated average of 2,000 square feet of floor space per home was derived from a postulated mix of two apartments of 1,000 square feet (each) to two houses of 2,000 square feet (each) to one house of 4,000 square feet; that is, such a mixture of sizes was assumed to be a plausible representation of the homes constructed with aluminum wiring. The resulting estimate of the national total of such homes is 1.45 million.

To make the estimates current, extrapolations were made to the end of 1974. (No new production data were obtained.) A lower bound was extrapolated by assuming no increase in annual production beyond 1971. Extrapolating from the estimate of 2 million gives an estimated 3.8 million homes by the end of 1974, and extrapolating from the 1.45 million figure results in an estimate of 2.8 million homes at the end of 1974 .

Higher estimates may be obtained by assuming that the $36 \%$ annual increase in aluminum wire production from 1969 to 1971 continued unimpeded through 1974. Extrapolating from the 2 million home estimate yields an estimate of 5.5 million homes as of the end of 1974, and extrapolating from the 1.45 million yields an estimate of 4 million homes by the end of 1974. These extrapolations ignore whatever effect the imposition and lifting of bans and other restrictions may have had.

These estimation procedures have been detailed here to impress upon the reader that this estimation is based on rather simple and arbitrary methods, and that the resulting estimates should not be interpreted as results of any extensive research. Without considerably more satisfactory data and considerably more refined estimation procedures (both of which may be impossible to attain) the most that can be said is that there are probably "at least a few million" homes wired with aluminum, and undoubtedly more than 1.5 million. Less cautious assertions are frequently hear, but they evidently are unsupportable. 


\subsection{Conclusion}

The search of field data has found that no available data have the characteristics necessary in order to develop a statistically sound estimate of the level of hazard associated with aluminum wiring. Neither do the available data establish the relation of aluminum to copper wiring in this regard.

But although the data do not establish statistically that there is a significant hazard, no more do they establish that there is not a hazard. There is, of course, ample evidence to suggest that there is a substantial hazard, but actual experience with the performance of aluminum wiring has varied widely. Similarly, there is no consensus regarding the remedies that are appropriate, although few of the persons contacted in this search were aware of the lack of consensus. It follows that until this lack of consensus is widely recognized, it is likely that any action that the CPSC might take would be viewed as inappropriate by many persons who think of themselves as knowledgeable in this area.

The extensive data requirements relevant to this study are entirely foreign to the operational data requirements of most of the organizations and officials contacted. Although there is no unwillingness to cooperate, some of the persons contacted do not appreciate that distinction in data requirements. Consequently it has not been sufficient to rely on verbal assurances that detailed documentary data are available; the extant records must be critically examined and subjected to validity checks. There are some collections of records that give a superficial impression of having the requisite characteristics. These are documentary data in the sense that they exist in the form of written documents. It is essential, however, to consider the somewhat subtle question of what is documented. In some cases fires are documented; in some cases, opinions; in some cases, estimates; in some cases, recollections of incidents long past. The UL surveys are examples of the creation of documentary information consisting largely of estimates based on recollections, even though the respondents themselves might not characterize their information this way. Such documentary data must not be accepted at face value, without assessment according to the criteria discussed previously (Section 3.2). Data obviously are not rendered valid merely by virtue of being in a signed document; assertions are not true merely by virtue of being attributed to documentary sources. Even the fact that a public authority has committed itself to a course of action restricting the use of aluminum wiring does not imply that aluminum wiring problems have been experienced within the respective jurisdiction.

There is no accurate estimate available on the extent to which aluminum wiring is now in use, i.e., how many homes employ aluminum conductors in various forms. Furthermore, the risks to the individual consumer -- i.e., his chances of experiencing problems with his electrical system, and the possible consequences of such problems -- are impossible to estimate accurately with presently existing information. 
In this climate of uncertainty the CPSC must make some determination of the next steps to be taken. The following section of this report begins by identifying alternative responses available to the Commission and concludes with a summary description of additional field data requirements and a brief discussion of the efforts entailed by a commitment to obtain these data.

\section{Satisfying the Data Requirements}

Sections 2 and 4 of this report have presented some of the actions and field data which have been used as bases for questioning the safety of using aluminum wiring in residential applications in this country. Section 3 outlined the data (and data characteristics) required to determine the extent of use of aluminum electrical wiring in U. S. residences, to determine the level of risk to consumers associated with its use, and to describe in detail the performance of aluminum electrical wiring as installed in residences. Section 4 also presented an evaluation of the existing field data in terms of the Section 3 criteria.

The information thus far presented has shown that while there have been problems in using aluminum wiring in residential applications, the existing field data are of neither sufficient quality nor sufficient quantity to make statistically defensible estimations of the nature and extent of aluminum wire use or of the level of risk to consumers of such use. The reason for this inadequacy is that a scientific determination would require (a) an extensive, and therefore expensive, data collection effort, (b) a sample design that represents all the important variables in aluminum wire applications, and (c) a consistent set of definitions and categories throughout the data collection. Section 4.2.1 noted that fire marshals and electrical inspectors had no need for such a rigorous data collection in order to carry out their duties.

Neither is the CPSC required by law to base its actions on statistically defensible findings. With regard to risks associate with aluminum wire, the CPSC has three choices. It can

- Judge that no "unreasonable" risk exists. In this case, no further action would be required.

- Judge that available information is not sufficient to establish whether an unreasonable risk exists, but acknowledge that the possibility of such risk exists. In this case, the CPSC would seek further expert advice and/or laboratory and field investigation. It must be noted that if an unreasonable risk to the consumer should now exist, further investigations could be at the expense of additional losses. 
- Judge that aluminum electrical wiring in residential applications presents an unreasonable risk to consumers. In this case, while further investigation would not necessarily be excluded, the CPSC would be required to make immediate recommendations leading to reduction of the level of risk. Such a judgment, then, presupposes sufficient knowledge to propose solutions.

Under the second choice, there remains a need for new field data for two purposes. The first is to establish the existence and extent of an unreasonable risk in the use of aluminum wiring. The second purpose is to establish the actual circumstances in which aluminum wire has been used (see Section 3.1.3) to provide guidance in establishing the initial conditions of laboratory experiments and in the interpretation of their results, in order to relate the experimental work to performance to be expected in the field.

If at any time the CPSC determines that there is an unreasonable risk, a different kind of data will be needed for effective implementation of CPSC recommendations or rulings. It will be necessary to identify the electrical inspection officials who ultimately will be involved in any new procedures for the use of aluminum wire (including remedial action that may be applied to existing installations), and this identification will not be simple since the jurisdictional organization of the electrical inspection function in this country is complex and fragmentary. It will be advisable to have measures of the existing inspection staffs, facilities, workloads and practices if it is proposed to place additional burdens on them.

The CPSC decision process need not be discussed further here. It is presented in order to make two points: CPSC judgments will influence the extent of future CPSC supported investigations, and CPSC decision criteria may influence the nature of future CPSC supported field data collection.

Section 5 presents a general outline of a field data collection effort which would meet the data requirements outlined in Section 3 . This effort assumes a desire on the part of CPSC to establish the level of risk associated with aluminum wiring at a moderate level of confidence, and a desire to recommend or implement remedial actions.

It must be noted that the procedures described below are not yet fully developed and would, therefore, be subject to modifications based on additional developmental work: The variables discussed will require operational definitions (which must relate both to data collection procedures and analytical tasks); the data collection procedures and operational definitions must be tested in situ, and revised as necessary; and samples must be designed to meet criteria which will be established by comparing desired levels of statistical confidence with economic and time constraints. 
The field data collection plan described in Section 5 involves two distinct types of data collection efforts. One, to determine the extent of aluminum wire use and to estimate the magnitude of effort required to correct any existing problems, is an extensive, nation-wide "macro" effort. The other, to identify the specific nature of any hazard and to estimate associated risks, is an intensive, localized "micro" effort. Logically, the work would proceed in a stepwise fashion; determining the level of risk first and then approaching the other tasks only as necessary. Time constraints, however, might dictate concurrent efforts so that if unreasonable risk were established, appropriate tasks could be readily performed.

\subsection{The Macro Study}

The characteristics of data to be sought in the field to determine the extent of use of aluminum electrical wiring and to determine the effort required to reduce or eliminate any hazard associated with its use were outlined in Section 3.1.1 and part of Section 3.1.2, and are repeated below.

- A representative set of all types of U. S. housing (single and duplex houses, apartments, mobile homes);

- A representative set of geographical areas;

- Categorization according to specific electrical application (branch circuit conductors, service entrance cable, appliance circuit conductors, service busbar conductors, and any combinations of these;

- Categorization according to relevant installation date (e.g., pre and post UL listing of CO/ALR devices). It would be highly desirable for the data to be categorized by type of connector AL-CU, copper pigtail, CO/ALR, "push" device, etc.) .

- Data concerning existing code requirements for electrical wiring in residences and the enforcement practices followed with respect to those codes. Identification of mechanisms and usual time intervals required to change these codes and/or procedures.

Data concerning the training and/or licensing required of electrical workers and electrical contractors, in order to identify expected workmanship and ways of influencing workmanship. 


\subsubsection{Sample for the Macro Study}

These data must be collected in such a way as to represent the national use of aluminum wire. The macro effort could best be accomplished by collecting the necessary data from a sample of electrical inspection jurisdictions drawn from all such jurisdictions in the United States. Since a nationwide enumeration of these jurisdictions is not available, the county (or county-equivalent) is probably the most reasonable substitute sampling unit.

A Census-derived enumeration of counties and county-equivalents exists, and use of this sampling unit would provide another advantage -for these sample units it is possible to obtain Census housing data. (It may be logically assumed that those areas with larger housing increases would be areas with possibly greater use of aluminum electrical wiring.) Using the list of counties, a stratified sampling plan would be designed according to residential construction rates. It may be possible to improve the accuracy of projections by increasing the sampling rate for the strata with higher construction rates.

Although in some instances county/county-equivalent may, in fact, be an electrical inspection jurisdiction, it is known that in some instances there are several electrical inspection jurisdictions within one county. In those sample counties containing multiple jurisdictions it would be necessary to identify and contact each separate jurisdiction.

\subsubsection{Data Collection for the Macro Study}

Within each jurisdiction, the source of data would be the chief electrical inspector or equivalent. In order to cover the time interval in question, it might be necessary to contact more than one person in each jurisdiction.

A data collection form has been partly developed to conform to the data required and the interviewing technique employed. Face-to-face interviews would probably be excluded because of cost constraints, so a combination of mail and telephone contacts is the recommended method.

The questions to be asked would address the following topics:

- organization of the electrical inspection function

- the inspector's knowledge and attitudes about copper, aluminum and coated aluminum (e.g., copper-coated or nickel-coated) wire

- inspection facilities, resources and workload

- inspection procedures and practices

- electrical codes and legal requirements, including specific requirements concerning usage of aluminum 
- numbers of dwelling units constructed, by type and time frame

- $\quad$ percentage of new units wired with aluminum

- by type of wire involved, numbers of installations of:

- $\quad$ service entrance or feeder cables

- $\quad$ appliance circuits with wired-in appliances

- $\quad$ appliance circuits with receptacles for plug-in appliances

- general purpose branch circuits:

- devices directly connected by binding-head screws

- devices installed by push-in connection

- devices installed by pigtail connection

- $\quad$ light fixtures

- others connections

- use of "new aluminum alloys"

- use of CO/ALR devices

- use of nonmetallic-sheathed cable

- use of nonmetallic boxes

\subsection{The Micro Study}

The field data required to determine the nature of any hazards caused by aluminum electrical wiring and to estimate the associated risks were outlined in section 3.1.3 and part of Section 3.1.2 and are repeated here.

Determination of Level of Risk:

- Data to establish the population of possible failures of aluminum wiring in a specified area. These data must be categorized by the other relevant factors including specific conductor application within residence, date of installation, etc.

- Data to establish numbers of failures in the same specified area (by specific application, by installation date). These data must also be categorized by type of failure: termination failure, wire failure, incipient failure, etc. 
- Data to establish the consequences of each failure in terms of occupant safety (by specific application, by installation date, etc.): fire or necessary conditions for fire, shock or necessary conditions for shock, etc. The data are specified in this way because actual injuries or deaths related to aluminum wire failures may be relatively rare events.

The data required for the determination of whether the risk is reasonable or not depends on decision criteria to be established by the CPSC. Possible data needs include data to compare the level or risk of aluminum wiring with other products, and/or data to compare the cost of one decision outcome with others:

- Comparable data for copper wiring as specified in the three items above.

- Data concerning the levels of risk associated with other products installed in homes.

- Data outlining the costs associated with any aluminum wiring hazard.

Determination of the Physical Nature of the Hazard:

- Environment of the connection, (e.g., temperature, humidity, vibration, etc.).

- Nature of the conductor, (e.g., size, specific application, etc.).

- Nature of the wiring device, (e.g., type, connection technique, applied voltage, etc.) .

- State of the connection, (e.g., loaded and unloaded resistance, evidence of creep or corrosion, etc.).

- Nature of the installation, (e.g., age, evidence of code violation, etc.).

- Nature of electrical system, (e.g., capacity of service box, line voltages, etc.).

- If failure, nature of the failure, (e.g., creep, corrosion, mechanical failure, etc.).

- If failure, alerting condition, (e.g., flicker in lights, odor, electrical shock, etc.). 
The micro study itself could be considered to have two distinct parts because the data required for estimating level of risk are qualitatively different from the data required to identify hazards per se. The former data could be collected by asking people to supply information, while the latter data would have to be collected by observing and measuring the actual performance of electrical wiring systems on site in homes. Both parts of the micro study as outlined here, however, would require collecting data about the performance of aluminum wìring in a set of residences.

\subsubsection{Sample for the Micro Study}

For both parts of the micro study, the population would probably be defined, for example, as all aluminum wire junctions in a specified area. Cluster sampling would then be used (i.e., residential units containing aluminum electrical wiring), and a sample of such clusters (residences) would be selected. Because of the nature of the analysis, the definition and enumeration (or estimation) of the population would be as important as, and could be as demanding as, the data collection itself.

The installations on which performance data would be sought would be subdivided in some or all of the following ways, depending on the cost entailed and the amount of detail sought in the conclusions to be developed. The installations would be subdivided according to their components, in order to preselect installations with"old" wire alloys and "old" (non-CO/ALR) devices, those with "new" alloys and "old" devices, and those with "new" alloys and CO/ALR devices. There might also be a geographic division to include three climates: (a) wet, warm and salty (southern coastal), (b) wet and cool (inland), and (c) dry and cool (inland). A division between aluminum and copper is, of course, necessary, and a group of installations using copper-coated aluminum would be desirable. It may be important to subdivide the sample by (or control for) other variables such as the quality of workmanship and the type of electrical code requirements.

Sample size and overall sample design and sample selection procedures would depend on further developmental work. The samples for the two parts of the micro study would be designed together; probably the sample for the engineering measurements to collect data on the nature of the hazard would be a subset of the sample for data on the level of risk.

\subsubsection{Data Collection for the Micro Study}

A form would be designed to collect engineering measurement data to identify any hazards associated with the use of aluminum wiring. This form would be suitable for recording measurements and observations made of the wiring system in each sample residence. It would be necessary to obtain permission and legal waivers to gain access to each residence and its wiring. (No measures or observations are proposed which would alter the state of the electrical system.) In this regard, it is assumed that data collection teams would work only in cooperation with the local electrical inspection authority and/or government. A most likely site for pretesting this data collection procedure would be military housing, because of the relative ease in gaining access. 
The purpose of the other part of the micro study is to estimate the degree of risk in relation to "exposure". to aluminum wiring, i:e., in relation to some defined quantity of aluminum wire in use. Data on the performance of the wire would be obtained by asking residents or others to report symptoms, not necessarily limited to fires or even to failures. On the one hand, the reported characterizations of performance would be related to the corresponding physical measurements, which in turn would be related to laboratory conditions. On the other hand, the performance characterizations would be assessed as to hazard potential: fire, predisposing conditions for fire, "primary shock hazards" (necessary conditions for shock), and "secondary shock hazards" (malfunctions that would tend to induce residents to expose themselves to shock hazards while attempting diagnosis or repair).

There are three basic approaches to this part of the micro study -the performance survey.* The first approach would sample dwellings according to a Census Bureau sampling plan. The second would sample in localities determined beforehand to have certain important characteristics. The third approach would direct the survey efforts to locations of known fires, and determine the characteristics afterward.

The first approach would utilize the dwelling sample employed in the Census Bureau's Quarterly Survey of Residential Alterations and Repairs. (The Census Bureau also has a Monthly Survey of Housing Starts, Sales and Completions, and an Annual Housing Survey, but these are not as suitable for the present purposes as the quarterly survey.) The chief advantage of this approach is that it would provide a nationally representative sample of housing units. Although there are repair data available from this source now, the level of detail is insufficient for the aluminum wire study. Thus the quarterly survey provides only a basis for

\footnotetext{
* A fourth approach has sometimes been suggested. It is statistical analysis of existing fire data for counties that are matched by demographic variables and paired by the type of conductor (aluminum and copper). It is unlikely that any counties can be accurately characterized as predominantly aluminum-wired. Smaller units (communities) that can be so characterized would be very difficult to satisfactorily match with demographically similar copper-wired communities (of the same age). Defects in the quality of existing fire data, such as those mentioned in Section 4.2.2, would preclude the use of data just for fires attributed to electrical causes, and would thus require that gross fire data (all causes, or perhaps all except arson) be lumped together. In order for a statistical analysis to detect among many variables a difference in fire rates, between aluminum and copper, would require that the difference be large in comparison with the lower rate (which may not be the case) or that the data base be very large (probably prohibitively large). Even if this approach were feasible, it would only give fire rates and would give no other performance data and no basis for relating symptoms to engineering measurements, since there would be no interviews and no measurements.
} 
further survey work. Due to confidentiality requirements of the Census Bureau, the initial contact with residents to be surveyed would have to be made by Census Bureau personnel; where a waiver can be obtained, subsequent survey contacts could be made by others. The necessity for Census personnel involvement in providing the sample and carrying out at least the first round of survey contacts (along with other Census Bureau obligations) would result in considerable time and expense. A further drawback is that very few aluminum installations would be obtained from this sample, and therefore the resulting statistics may be of little value in determining the performance of aluminum wire. Furthermore, this approach depends on the resident to know what type of wire he has, and therefore will result in a substantial proportion of nonresponses and incorrect responses.

The second approach would select communities known (primarily from builders and contractors) to have the types of wire and devices of interest (along with the other sample design characteristics such as climate). This sampling design does not depend on the resident's knowing whether he has aluminum or copper wiring. Because the performance data would be obtained by asking residents about symptons, and this in itself tends to bias the respondent, it is essential that this survey design include a control group, i.e., a group of dwellings wired with copper, to allow valid comparisons to be made. This approach would require careful consideration of the tradeoff between cost and statistical quality. Cost constraints might so limit the sample size that the results could only be regarded as "typical" but not nationally representative, with a consequent danger of being misleading in the same way that some existing data are.

The third approach would concentrate on fires, and would obtain fire data of the requisite detail and quality by investigating fires specifically for the purposes of this study. For a few months, all fires occurring in certain jurisdictions would be screened by local fire officials to identify those of potential interest to this study. Participating fire officials would be trained as necessary, and their departments probably would have to be paid for the burden that the study would place on them. It is anticipated that about ten fire departments covering appropriate geographic areas would have the technical competence and willingness to participate. Fires of potential interest would be reported by telephone to the study staff, and in many cases a staff member would go immediately to the fire site to investigate further. Measurements would also be made at matched buildings where no fire occurred. When possible, residents where the fires occurred would be interviewed. The chief drawback of this approach, aside from the usual problems of cost and sample size, would be a sample bias toward installations that had fires, with a less than proportionate sampling of non-fire performance. Further, residents where the fires occurred may be unavailable and undoubtedly would be biased by recent experiences.

Of these three approaches to the performance survey, the first is least likely to be feasible, due to the high expense combined with the little likelihood of useful results. The second approach would seem to be most promising, since its sample design does not have the bias of 
the third approach. However, the choice would eventually depend on the joint evaluation of cost and statistical quality, which in turn would depend on detailed sample design and procedure development work.

\subsection{Summary}

To develop a measure of the national hazard potential associated with the use of aluminum wiring and a corresponding measure for copper wiring as a baseline for comparison, two types of data not now available would have to be collected. The first would be data on the extent of use of aluminum wiring, obtained from an extensive, nationwide "macro" survey of electrical inspectors. The second type of data would be risk data obtained from an intensive, localized "micro" survey of dwellings. These two surveys would mostly address the issue of hazard, but would also develop some data to solve whatever problems may be identified.

The CPSC is not required to base its rulings on hazard data of the statistical quality contemplated here, and thus would not need to undertake the surveys described here, if in its judgment an adequate alternative basis for a ruling exists. However, implementation of regulatory measures may require some of the data that would be developed by the macro survey, and laboratory experiments require field data of the type that the micro survey would develop if the experiments are to be related to performance of aluminum wire in residential use.

The data collection plan discussed in Section 5 is necessarily very general. Although a significant amount of development work has been done, a significant amount still remains to be done before exact procedures can be stated. Included in the required developmental work are two important conceptual activities -- operational definition of variables and the mathematical formulation of the analytical tasks in terms of these variables. (It should be noted that these two processes are highly interrelated and iterative.) The design of samples and specification of exact procedures will in large measure depend on this conceptual work. Cost estimation would depend on the sampling design and data collection procedures.

Procedures for the macro study are more straightforward than those for the micro study. Therefore, although these activities would be initiated concurrently, it is assumed that the macro data collection could be initiated more quickly than the micro activity. 


\section{REFERENCES}

1. Mutual Substitutability of Aluminum and Copper, A Report of the National Materials Advisory Board, NMAB 286, April 1972, p. 36.

2. Ltr. from Baron Whitaker, President of Underwriters' Laboratories, Inc. to the Honorable John E. Moss, Congressman from California. April 7, 1972.

3. Underwriters' Laboratories, Inc. Bulletin of Research Number 48, "Aluminum Building Wires and Connectors," September 1954, p. 5.

4. Inter-Office Memorandum from T. Gregory to P. Mara of The Aluminum Association, "Estimated Shipments of Aluminum Electrical Building Wire, 1960-1971". April 28, 1972.

5. Op. Cit., Mutual Substitutability of Aluminum and Copper, pp. 9 and 36.

6. F. Hehre and G. Harness, Electrical Circuits and Machinery. Volume I, Direct Currents, John Wiley \& Sons, Inc., New York, 1940, p. 96.

7. Op. Cit., Mutual Substitutability of Aluminum and Copper, p. 36

8. Ibid, pp. 12-14.

9. Ltr. from Underwriters' Laboratories, Inc. to the Electrical Council of Underwriters' Laboratories, Inc. and Manufacturers of General Use Snap Switches and Attachment Plug Receptacles. August 18, 1966.

10. Op. Cit., UL Bulletin of Research Number 48.

11. Battelle Proposal and Past Research on Aluminum Wiring, c. 1973.

12. Op. Cit., Ltr. from Whitaker to Moss, April 7, 1972.

13. Tape transcription of presentation on aluminum wiring by Capt. Carl L. Duncan, Huntington Beach Fire Department, Huntington Beach, California, January 20, 1971.

14. Op. cit., Ltr. from Whitaker to Moss. April 7, 1972.

15. Ltr. to Leviton Distributors. March 10, 1972.

16. Ltr. from Circle F Manufacturers to all Circle F Customers. April 6, 1972.

17. Conversations with Thomas D'Agostino of Underwriters' Laboratories, Inc. February and March 1974. 
18. National Fire Codes, 1972-73 ed., Volume 5.

19. This information was provided by Inspector Robert J. Kelly of the Washington, D. C. Fire Department, during a seminar at NBS on January 21, 1974. The two investigators referred to are himself and Capt. Carl L. Duncan of the Huntington Beach (California) Fire Department.

20. Conversation with Mr. Melvin Young, Chief Electrical Inspector of Fairfax County, Virginia, January 9, 1974.

21. Ltr. from G. E. Scha11, Jr. of Underwriters' Laboratories, Inc. to J. J. Kirk of the National Electrical Manufacturers Association. March 31, 1970. p. 2

22. Speech by the Honorable John E. Moss, Congressman from California, to the National Association of Homebuilders. Houston, Texas. January 8, 1973.

23. Battelle Proposal and Past Research on Aluminum Wiring, c. 1973.

24. Op. Cit., Ltr. from Schall to Kirk. March 31, 1970. p. 7.

25. Ibid.

26. Memo from Baron Whitaker of Underwriters' Laboratories, Inc. to Members of the Ad Hoc Committee on the Use of Aluminum Conductors with Wiring Devices in Electrical Wiring Systmes. May 21, 1973.

27. Underwriters' Laboratories, Inc. Tabular Report, 'Underwriters' Laboratories Survey: Aluminum Wire Terminations". February, 1973.

28. Conversation with Mr. L. E. LaFehr, Executive Vice President of the International Association of Electrical Inspectors. January 23, 1974.

29. Op. Cit., Memo from Whitaker to Ad Hoc Committee. May 21, 1973.

30. Ibid.

31. Attachment "About the Questionnaire" to letter of March 25, 1974, from UL President Baron Whitaker to Jacob Rabinow, NBS.

32. Ibid.

33. Wa11 Street Journa1, September 22, 1972.

34. Conversation with Richard Sumner, Assistant Vice President and General Manager of the Underwriting Department of American P1an Corporation, March 11, 1974. 


\section{References (continued)}

35. IAEI News, September-October 1974, pp. 30-31, International Association of Electrical Inspectors, Park Ridge, Illinois.

36. Conversations with Joseph Kuntz, Chief Electrical Inspector of Prince George's County, Maryland, on February 25 and 28, 1974.

37. Conversation with Mr. William Meyer, Chief Electrical Inspector of Washington, D. C., March 13, 1974.

38. Letter from Carl L. Duncan, Deputy Fire Marshal of Huntington Beach, California to O1lin C. Cleveland, Building Director of Huntington Beach, June 1, 1971.

39. Conversation with Joseph Kuntz, Chief Electrical Inspector of Prince George's County, Maryland, February 28, 1974.

40. Op. Cit., Inter-Office Memorandum from Gregory to Mara, April 28, 1972.

41. Ltr. from Lawrence M. Kushner, Acting Director of NBS to the Honorable John E. Moss, Congressman from California, October 20, 1972.

42. Conversation with Mr. Skinkle of the NAHB Research Foundation, February 5, 1974. 
NBS-114A (REV. 7.73)

\begin{tabular}{|c|c|c|c|}
\hline $\begin{array}{l}\text { U.S. DEPT. OF COMM. } \\
\text { BIBLIOGRAPHIC DATA } \\
\text { SHEET }\end{array}$ & $\begin{array}{l}\text { 1. PUBLICATION OR REPORT NO. } \\
\text { NBSIR 75-677 }\end{array}$ & $\begin{array}{l}\text { 2. Gov't Accession } \\
\text { No. }\end{array}$ & 3. Recipient's Accession No. \\
\hline \multirow{2}{*}{\multicolumn{3}{|c|}{$\begin{array}{l}\text { 4. TITLE AND SUBTITLE } \\
\text { HAZARD ASSESSMENT OF ALUMINUM ELECTRICAL WIRING IN } \\
\text { RESIDENTIAL USE }\end{array}$}} & $\begin{array}{l}\text { 5. Publication Date } \\
\text { December } 1974\end{array}$ \\
\hline & & & 6. Performing Organization Code \\
\hline \multicolumn{3}{|c|}{$\begin{array}{l}\text { 7. AUTHOR(S) } \\
\text { Elaine D. Bunten, John L. Donaldson, Eugene C. McDowe11 }\end{array}$} & 8. Performing Organ. Report No. \\
\hline \multicolumn{3}{|c|}{$\begin{array}{l}\text { 9. PERFORMING ORGANIZATION NAME AND ADDRESS } \\
\text { NATIONAL BUREAU OF STANDARDS } \\
\text { DEPARTMENT OF COMMERCE } \\
\text { WASHINGTON, D.C. } 20234\end{array}$} & $\begin{array}{l}\text { 10. Project/Task/Work Unit No. } \\
4410104 \\
\text { 11. Contract/Grant No. }\end{array}$ \\
\hline \multirow{2}{*}{\multicolumn{3}{|c|}{$\begin{array}{l}\text { 12. Sponsoring Organization Name and Complete Address (Street, City, State, ZIP) } \\
\text { U. S. Consumer Product Safety Commission, } \\
\text { Washington, D. C. } 20207\end{array}$}} & $\begin{array}{l}\text { 13. Type of Report \& Period } \\
\text { Covered } \\
\text { Final }\end{array}$ \\
\hline & & & 14. Sponsoring Agency Code \\
\hline
\end{tabular}

16. ABSTRACT (A 200-word or less factual summary of most significant information. If document includes a significant bibliography or literature survey, mention it here.)

In the mid-1960s, aluminum wire began to be used in significant quantities for residential branch-circuit wiring. Reports of problems from various localities in the U.S. raised serious concern and controversy as to the safety of this application. An official determination on this matter is within the jurisdiction of the Consumer Product Safety Commission. This report reviews the history of the use of aluminum in residential wiring and describes the characteristics essential to data to be used to evaluate the performance of aluminum wiring in the field. The examination of existing field data shows that no available data have the characteristics necessary to develop a reliable estimate of the level of risk to consumers associated with aluminum wiring. Neither can the available data be used to establish the relative risk of aluminum compared to copper wiring. There is only a gross estimate of the extent to which aluminum wiring is now in use in U.S. residences. Statistically sound estimates of risk would be possible only after data collection on a large scale.

17. KEY WORDS (six to twelve entries; alphabetical order; capitalize only the first letter of the first key word unless a proper name; separated by semicolons)

Aluminum wire; consumer product safety; electrical failures; electrical fires; electrical wiring; fire hazards

18. AVAILABILITY

$$
\text { XX Unlimited }
$$

For Official Distribution. Do Not Release to NTIS

Order From Sup. of Doc., U.S. Government Printing Office Washington, D.C. 20402, SD Cat. No.C13

$\square$ Order From National Technical Information Service (NTIS) Springfield, Virginia 22151

\begin{tabular}{|l|c|}
\hline $\begin{array}{l}\text { 19. SECURITY CLASS } \\
\text { (THIS REPURT) }\end{array}$ & 21. NO. OF PAGES \\
UNCL ASSIFIED & 56 \\
\hline $\begin{array}{l}\text { 20. SECURITY CLASS } \\
\text { (THIS PAGE) } \\
\text { UNCLASSIFIED }\end{array}$ & 22. Price \\
\hline
\end{tabular}

